Subscriber access provided by King Abdullah University of Science and Technology Library

\title{
Article
}

\section{Dynamics of Intercalation/De-Intercalation of Rhodamine B during the Polymorphic Transformation of CdAl Layered Double Hydroxide to the Brucite-Like Cadmium Hydroxide}

Daniel Saliba, Alaa Ezzeddine, Abdul-Hamid Emwas, Niveen M Khashab, and Mazen Al-Ghoul Cryst. Growth Des., Just Accepted Manuscript • DOI: 10.1021/acs.cgd.6b00455 • Publication Date (Web): 23 Jun 2016

Downloaded from http://pubs.acs.org on June 28, 2016

\section{Just Accepted}

"Just Accepted" manuscripts have been peer-reviewed and accepted for publication. They are posted online prior to technical editing, formatting for publication and author proofing. The American Chemical Society provides "Just Accepted" as a free service to the research community to expedite the dissemination of scientific material as soon as possible after acceptance. "Just Accepted" manuscripts appear in full in PDF format accompanied by an HTML abstract. "Just Accepted" manuscripts have been fully peer reviewed, but should not be considered the official version of record. They are accessible to all readers and citable by the Digital Object Identifier (DOI®). "Just Accepted" is an optional service offered to authors. Therefore, the "Just Accepted" Web site may not include all articles that will be published in the journal. After a manuscript is technically edited and formatted, it will be removed from the "Just Accepted" Web site and published as an ASAP article. Note that technical editing may introduce minor changes to the manuscript text and/or graphics which could affect content, and all legal disclaimers and ethical guidelines that apply to the journal pertain. ACS cannot be held responsible for errors or consequences arising from the use of information contained in these "Just Accepted" manuscripts. 


\title{
Dynamics and Mechanism of Intercalation/De-Intercalation of
}

\section{Rhodamine B during the Polymorphic Transformation of the}

CdAl Layered Double Hydroxide to the Brucite-Like

\author{
Cadmium Hydroxide
}

\author{
Daniel Saliba, ${ }^{\dagger}$ Alaa Ezzeddine, ${ }^{*}$ Abdul-Hamid Emwas, ${ }^{\S}$ Niveen M. Khashab, ${ }^{\star}$ and \\ Mazen Al-Ghoul ${ }^{*} \dagger$ \\ ${ }^{\dagger}$ Department of Chemistry, American University of Beirut, P.O.Box 11-0236, Riad El- \\ Solh 1107 2020, Beirut, Lebanon \\ $\$$ Smart Hybrid Materials (SHMs) Lab, King Abdullah University of Science and \\ Technology (KAUST), Thuwal 23955-6900, Kingdom of Saudi Arabia \\ § Imaging and Characterization Core Lab, King Abdullah University of Science \\ and Technology (KAUST), Thuwal, Kingdom of Saudi Arabia \\ E-mail: mazen.ghoul@aub.edu.lb
}

Phone: +961 (1)350000. Fax: +961 (1)365217 


\begin{abstract}
We study the kinetics of intercalation of a fluorescent probe (Rhodamine $B(R h B)$ ) during the formation of hierarchal microspheres of Cadmium-Aluminum layered double hydroxide (CdAlA LDH) and its de-intercalation upon transformation from the LDH phase into the cadmium hydroxide $\beta$ phase $\left(\mathrm{Cd}(\mathrm{OH})_{2}\right)$ using a reaction-diffusion framework (RDF) where the hydroxide anions diffuse into an agar gel matrix containing the proper salts-fluorescent probe mixture. In this framework, we achieve the stabilization of the CdAlA LDH, which is known to be thermodynamically unstable and transforms into $\mathrm{Cd}(\mathrm{OH})_{2}$ and $\mathrm{Al}(\mathrm{OH})_{3}$ in a short period. RDF is advantageous as it allows with ease the extraction of the co-synthesized polymorphs and their characterization using X-ray diffraction (XRD), differential scanning calorimetry (DSC), thermal gravimetric analysis (TGA), solid-state nuclear magnetic resonance (SSNMR), Fourier transform infrared (FT-IR) and energy dispersive X-ray (EDX). The kinetics of inter/de-intercalation is studied using in situ steady-state fluorescence measurements. The existence of RhB between the LDH layers and its expel during the transition into the $\beta$ phase are examined via fluorescence microscopy, XRD, and SSNMR. The activation energies of intercalation and de-intercalation of $\mathrm{RhB}$ are determined and show dependence on the cationic ratio of the corresponding $\mathrm{LDH}$. We find that the energies of de-intercalation are systematically higher than those of intercalation indicating that the dyes are stabilized due to the probebrucite sheets interactions. SSNMR is used to shed light on the mechanism of intercalation and stabilization of $\mathrm{RhB}$ inside the layers of the $\mathrm{LDH}$.
\end{abstract}




\section{Keywords}

Layered double hydroxides, brucite, reaction-diffusion, intercalation, de-intercalation, polymorphic transformation, fluorescence.

\section{INTRODUCTION}

LDHs, also termed hydrotalcite-like compounds, are anionic clays endowed with a wide variety of applications in various scientific processes (catalysts precursors, catalysts, etc. $)^{1-3}$. The structure of these LDHs is better understood starting from that of the brucite compounds, $\mathrm{M}(\mathrm{II})(\mathrm{OH})_{2}$, where the divalent metal cations $(\mathrm{M}(\mathrm{II}))$ are octahedrally surrounded by hydroxyl groups which share edges to form infinite neutral sheets ${ }^{4}$. The stacking of these sheets on top of each other forms a tridimensional structure, the brucite compounds. The random substitution of some of the divalent cations by trivalent ones generates an excess in the positive charges in the sheets ${ }^{1,5}$. It results in the intercalation of some charge-balancing anions accompanied with water and/or other neutral molecules in the interlayer region to reestablish the electroneutrality of the compound, thus forming anionic LDHs. In addition to the intercalation of small anions (such as chlorides, nitrates, and bromides), larger anions, including biomolecules and polyelectrolytes, can also intercalate. For example, graphene oxide nanosheets were intercalated into a Calcium/Aluminum LDH rendering the material amenable to many interesting and diverse functions including electronic applications ${ }^{6}$, arsenate removal from water ${ }^{7}$, and electrochemical and bio-sensing ${ }^{8}$. Generally, the chemical formula of anionic LDHs is $\left[\mathrm{M}(\mathrm{II})_{1-\mathrm{x}} \mathrm{M}(\mathrm{III})_{\mathrm{x}}(\mathrm{OH})_{2}\right]^{\mathrm{x}+}\left(\mathrm{A}_{\mathrm{x} / \mathrm{n}}^{\mathrm{n}-}\right) \cdot \mathrm{mH}_{2} \mathrm{O}$, namely $\mathrm{M}(\mathrm{II}) \mathrm{M}(\mathrm{III}) \mathrm{A}$, where $\mathrm{M}(\mathrm{II})$ is the divalent 
metal cation and $\mathrm{M}(\mathrm{III})$ is the trivalent metal cation. $\mathrm{A}^{\mathrm{n}-}$ is the guest anion and ' $x$ ' is the cationic ratio defined as $x=\mathrm{M}(\mathrm{III}) /(\mathrm{M}(\mathrm{III})+\mathrm{M}(\mathrm{II}))$ where $0.20 \leq x \leq 0.40^{1,4,5,9-12}$. Recently, despite the generally accepted claim ${ }^{13}$ that only ionic radii ranging between 65 pm and $89 \mathrm{pm}$ for divalent cations and $62 \mathrm{pm}$ and $69 \mathrm{pm}$ for trivalent cations can form stable LDH structure, complex hierarchical microspheres of Cadmium-Aluminum layered double hydroxide $\left(r_{\mathrm{Cd}}=109 \mathrm{pm}\right)$ were synthesized using a reaction-diffusion framework (RDF) and shown to exhibit interesting photocatalytic activity for the reduction of carbon dioxide ${ }^{14}$.

In this paper, we aim to continue to explore the CdAlA LDH and hereby present a study of the intercalation of a fluorescent dye, Rhodamine B (RhB), during the formation of the CdAlA LDH and the de-intercalation of this dye during the transition from the CdAlA LDH into the $\beta-\mathrm{Cd}(\mathrm{OH})_{2}$ (Fig. 1) using RDF in combination with in situ steady-state and time-resolved fluorescence spectroscopy. O'Hare and co-workers ${ }^{15}$ monitored the intercalation of a limited number of hosts in some LDH (LiAl and CaAl LDHs) using in situ energy dispersive X-ray diffraction (EDXRD). This in situ method permitted the detection of metastable species, known as staging intermediates, during the intercalation and de-intercalation processes. Accordingly, they were able to examine the kinetics of intercalation using a solid-state reaction model derived by Avrami, where the collected data was fitted with the Avrami-Erofe'ev equation and the activation energies (Ea) were calculated $^{15}$. Also, they were able to detect the phase conversion of some LDH-like compounds $\left(\alpha-\mathrm{Co}(\mathrm{OH})_{2}\right)$ to brucite-like compounds $\left(\beta-\mathrm{Co}(\mathrm{OH})_{2}\right)$ using in situ small/wide angle X-ray scattering (SAXS/WAXS $)^{16}$. These methods are restricted to slow transformations and are only applicable to a narrow class of LDHs such as LiAl and CaAl 
LDHs. Thus for other types of LDHs (such as MgAl LDH, FeAl LDH), where reactions are fast, it is impossible to determine the kinetic parameters.

RDF provides an alternative to the aforementioned technique and allows the calculation of the kinetic parameters of intercalation/de-intercalation of $\mathrm{RhB}$, for a range of $\mathrm{LDH} /$ brucite compounds.

$\mathrm{RhB}$ (Fig. $\mathrm{S} 1(\mathrm{~A}, \mathrm{~B}))$ is a xanthene derivative emitting in the red $(550 \mathrm{~nm}$ to $640 \mathrm{~nm})$ region of the visible spectrum. $\mathrm{RhB}$ is a cationic probe in acidic medium and a neutral one in basic solution ${ }^{17}$. We will see that one advantage of RDF lies in the ability to intercalate, with ease, neutral molecules such as $\mathrm{RhB}$ inside layered and porous material. The excitation and emission spectra, in addition to the lifetime values of RhB are sensitive to the changes in the molecular environment of the dye ${ }^{18-20}$, providing useful information about the conformation and dynamics of the dye itself in the corresponding medium $^{21}$. 


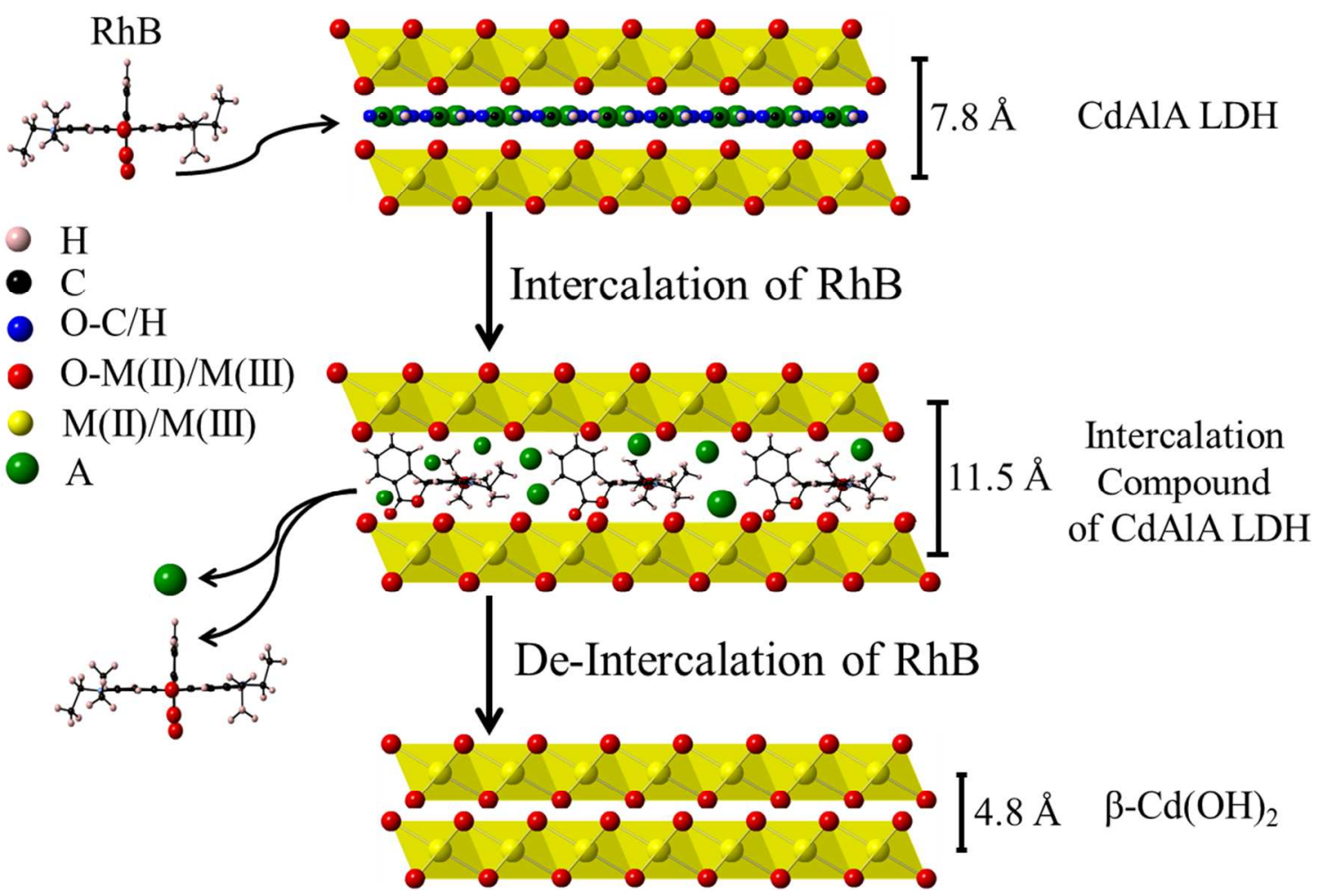

Figure 1. Schematic representation of $\mathrm{RhB}$ intercalation between the brucite-like sheets of the $\mathrm{CdAlA} \mathrm{LDH}$ and its de-intercalation during the polymorphic transformation into the $\beta-\mathrm{Cd}(\mathrm{OH})_{2}$.

\section{THE REACTION-DIFFUSION FRAMEWORK}

In our group, we work within a reaction-diffusion framework (RDF) where an outer electrolyte solution is poured on top of an agar gel matrix containing the inner electrolytes. The concentrations of the inner and outer electrolytes are chosen so that a supersaturation gradient is established through the reactor (a tube in this work). This supersaturation gradient furnishes a propagating front leading to the growth of the solid product in its wake. The gel plays a major role in the method for many reasons. First, it provides solid support for the reaction mixture allowing the reactants to diffuse without any convective forces or sedimentation. Second, it slows down the nucleation and growth 
processes allowing the product extraction at any time. Finally, it provides a suitable platform to perform with ease in situ analysis of the reaction zone. Recently, the cosynthesis of $\beta-\mathrm{Co}(\mathrm{OH})_{2}$ and $\alpha-\mathrm{Co}(\mathrm{OH})_{2}$ was also reported using $\mathrm{RDF}^{22}$. RDF allowed the study of the kinetics of inter and de-intercalation of anions during the formation of the LDH-like, $\alpha-\mathrm{Co}(\mathrm{OH})_{2}$, and its polymorphic transformation into the $\beta$ phase, $\beta-\mathrm{Co}(\mathrm{OH})_{2}$, via fluorescence spectroscopy ${ }^{23}$. The intercalation and de-intercalation activation energies of anions were calculated and showed that the polymorphic transition was accompanied by an Ostwald ripening mechanism ${ }^{23}$.

\section{EXPERIMENTAL}

\section{Materials}

All the chemicals were used without any further purification. Rhodamine B, cadmium chloride, cadmium nitrate, aluminum chloride, aluminum nitrate and sodium hydroxide pellets were supplied by Sigma-Aldrich. Agar gel was purchased from Invitrogen.

\section{Preparation Method}

We prepare stock solutions, using double distilled water, of the desired salts mixtures (e.g. aluminum chloride and cadmium chloride) with cationic ratio ' $x$.' We then add a certain amount $(1 \% \mathrm{w} / \mathrm{w})$ of agar gel weighed using an analytical balance. Next, we heat and stir the mixture until total dissolution of the gel and we transfer the gel-salts solution into a test tube. We leave the mixture (inner electrolyte) for 2 hours to polymerize, at constant ambient temperature. After complete gelation, $1 \mathrm{M}$ of sodium hydroxide (outer electrolyte) is poured into the tube provoking the initiation of the reaction-diffusion 
process. The tube is left for two days to allow the formation of both polymorphs, CdAlA LDH and $\beta-\mathrm{Cd}(\mathrm{OH})_{2}$ (Fig. 2). The extraction of the solids consists of separating the white $\left(\beta-\mathrm{Cd}(\mathrm{OH})_{2}\right)$ and yellow $(\mathrm{CdAlA} \mathrm{LDH})$ bands and washing them apart in two different beakers containing double distilled water and under continuous heating $\left(\sim 80^{\circ} \mathrm{C}\right)$ to redissolve the agar gel. We then separate the solid from the solution by centrifugation of the mixture. Finally, we freeze dry the extracted solid for 12 hours and we recollect it for analysis.

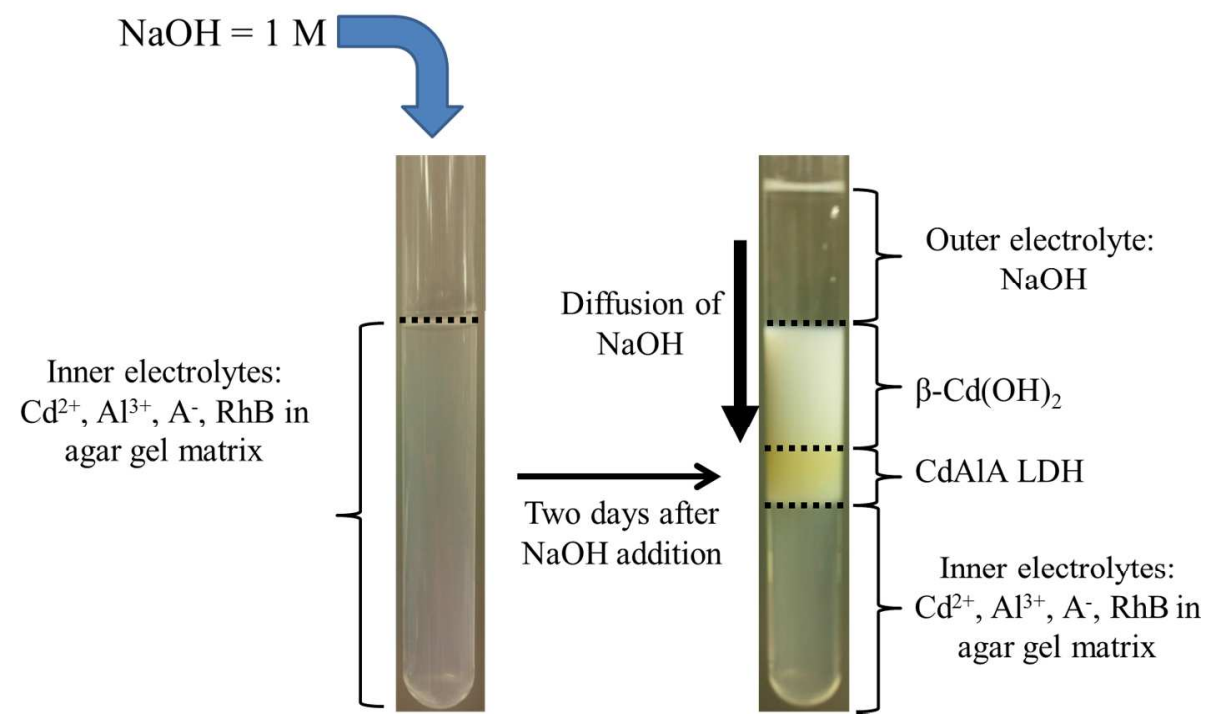

Figure 2. Schematic representation of the co-precipitation of the $\beta-\mathrm{Cd}(\mathrm{OH})_{2}$ brucite-like crystals and the CdAlA LDH.

\section{Polymorphs Characterization}

X-ray powder diffraction (XRD) patterns were carried out by a Bruker D8 Advance XRD diffractometer using $\mathrm{Cu}-\mathrm{K} \alpha$ radiation $(\lambda=0.15406 \mathrm{~nm})$ at $40 \mathrm{kV}$ and $40 \mathrm{~mA}$, ranging from $5^{\circ}$ to $50^{\circ}$ at a scanning rate of $2 \%$ min and a step size of $0.01 \mathrm{sec}$. Detector scan, rocking curve and Z-alignment were performed to achieve a better focusing of the X-Ray 
beam. The powder samples were supported on a silver holder via glass slides and the analysis time was 6 hours for all samples. Fourier transform infrared (FT-IR) spectra were recorded on a Thermo Nicolet 4700 Fourier transform infrared spectrometer equipped with a class 1 laser. Powdered samples were mixed with $\mathrm{KBr}$ (containing $5 \mathrm{wt} \%$ sample) then a disk-shaped pellet was formed. The thermal behavior of the precipitates was studied using thermal gravimetric analysis (TGA) on a TG 209 F1 Iris (Netzsch, Germany), in nitrogen atmosphere and a temperature range from $40{ }^{\circ} \mathrm{C}$ to $500{ }^{\circ} \mathrm{C}$, with a heating rate of $10^{\circ} \mathrm{C} / \mathrm{min}$. The thermal decomposition of the products was also studied using a differential scanning calorimeter (DSC 204 F1 Phoenix, Netzsch, Germany). The heating rate was $10^{\circ} \mathrm{C} / \mathrm{min}$ under a nitrogen atmosphere with a flow rate of $40 \mathrm{~mL} / \mathrm{min}$. ${ }^{13} \mathrm{C}$ solid-state nuclear magnetic resonance (SSNMR) experiments were conducted using a Bruker 400 MHz SS-NMR AVANCE III spectrometer (Bruker Bio Spin, Rheinstetten, Germany). All samples were prepared by packing $50 \mathrm{mg}$ of the samples in standard $4 \mathrm{~mm}$ zirconia rotors from Bruker and sealed at the open end with a Vespel cap. ${ }^{13} \mathrm{C}$ cross polarization magic angle spinning (CP MAS) NMR spectra were recorded at a resonance frequency of $100.622 \mathrm{MHz}$ under $12 \mathrm{kHz}$ spinning rate. To achieve high signal to noise ratio, the spectra were recorded by collecting $6 \mathrm{k}$ scans with a recycle delay time of $7 \mathrm{sec}$. The cross-polarization (CP) contact time was set to $2 \mathrm{~ms}$ employing ramp 100 for variable amplitude CP. The ${ }^{27}$ Al SSNMR spectra were recorded by collecting 1024 transients with $2 \mathrm{sec}$ recycle delay at $14 \mathrm{kHz}$ spinning rates using WB AVANCE III 400 MHz SS NMR spectrometer equipped with a Double Resonance Broadband BB/1H 4 $\mathrm{mm}$ Bruker $\mathrm{CP} / \mathrm{MAS}$ probe. The duration of excitation pulse was set to $2 \mu \mathrm{s}$ at an excitation power level of $56.3 \mathrm{~W}$, and the spectral width was set to $480 \mathrm{ppm}$. Prior to Al 
acquisition, the Al chemical shift was optimized using aluminum hydroxide as external reference. The EDX characterization of iridium-coated samples was performed on EDX from Ametek with a retractable EDAX detector model Appolo XL mounted on Quanta 600 FEG from FEI running at $2.0 \mathrm{kV}$. The fluorescence micrographs were taken using a Nikon Eclipse Ti. All the photographs were taken by a Nikon DS-Fi1C camera and under same conditions of light power and intensity. The steady-state fluorescence measurements were recorded using a Varian fluorescence spectrophotometer (Cary Eclipse), where the excitation and emission slits were $5 \mathrm{~nm}$ and $2.5 \mathrm{~nm}$ respectively, and the photomultiplier tube (PMT) voltage was $700 \mathrm{~V}$. All the fluorescence measurements were performed in a $5 \mathrm{~mL}$ fluorescence cuvette containing the inner electrolytes in gel medium together with $0.1 \mu \mathrm{M}$ of $\mathrm{RhB}$ as a fluorescent probe. The excitation and emission spectra were carried out in front face geometry by focusing the beam on the LDH formation front to detect the intercalation and on the $\mathrm{LDH} /$ brucite interface to detect the de-intercalation of the RhB molecules. The temperature was controlled by connecting an external thermostat to the sample holder. Time resolved fluorescence spectra were recorded using a Jobin-Yvon-Horiba Fluorolog III fluorometer operating at $800 \mathrm{~V}$. The powder sample was excited with a $458 \mathrm{~nm}$ pulsed light. The detection rate $(\alpha)$ was 1 photon for each 100 excitation pulses and the peak preset was 25000 counts. Finally, Data Analysis Software was used for decay fitting.

\section{RESULTS AND DISCUSSION}

The extracted precipitates (yellow $(\mathrm{CdAlA} \mathrm{LDH})$ and white $\left(\beta-\mathrm{Cd}(\mathrm{OH})_{2}\right)$ are characterized using a range of spectroscopic techniques. Fluorescence microscopy, XRD, 
and SSNMR are applied to investigate the presence of RhB. Finally, the kinetics of intercalation and de-intercalation are examined using steady-state and time-resolved fluorescence spectroscopy.

\section{Chemical Composition}

The stoichiometry of each LDH is determined based on the analysis of the TGA curves (Fig. S2) and the EDX data (Fig. S3). Therefore, the amount of water (adsorbed and intercalated) is determined from the TGA measurements ${ }^{24}$; the cationic ratio ' $x$ ' of the LDHs and the quantity of intercalated anions (chlorides and nitrates) are calculated from the atomic percentages given by the EDX spectra. Finally, the exact amount of carbonates is calculated from the TGA data ${ }^{24}$. The obtained empirical formulas for different CdAlA LDHs are given in table 1.

The chemical composition of the $\beta$ phase is also determined from the atomic composition data given by the EDX spectrum (Fig. S4). The chemical formula of the $\beta$ phase resulting from the polymorphic transformation of all CdAlA LDHs is $\mathrm{Cd}(\mathrm{OH})_{2}$, where the atomic ratio $\mathrm{O} / \mathrm{Cd}$ varies between 1.9 and 2.05. The absence of the aluminum hydroxide $\mathrm{Al}(\mathrm{OH})_{3}$ phase is due to its dissolution in excess diffusing hydroxide ions.

Table 1. Empirical formulas of different CdAlA LDHs.

\begin{tabular}{|c|c|}
\hline & $x=0.25$ \\
\hline $\mathrm{A}=\mathrm{Cl}^{-}$ & {$\left[\mathrm{Cd}_{0.75} \mathrm{Al}_{0.25}(\mathrm{OH})_{2}\right](\mathrm{Cl})_{0.19}\left(\mathrm{CO}_{3}\right)_{0.03} .0 .4 \mathrm{H}_{2} \mathrm{O}$} \\
\hline $\mathrm{A}=\mathrm{NO}_{3}^{-}$ & {$\left[\mathrm{Cd}_{0.75} \mathrm{Al}_{0.25}(\mathrm{OH})_{2}\right]\left(\mathrm{NO}_{3}\right)_{0.17}\left(\mathrm{CO}_{3}\right)_{0.04 \cdot 0.39 \mathrm{H}_{2} \mathrm{O}}$} \\
\hline & $x=0.33$ \\
\hline $\mathrm{A}=\mathrm{Cl}^{-}$ & {$\left[\mathrm{Cd}_{0.67} \mathrm{Al}_{0.33}(\mathrm{OH})_{2}\right](\mathrm{Cl})_{0.25}\left(\mathrm{CO}_{3}\right)_{0.04} \cdot 0.4 \mathrm{H}_{2} \mathrm{O}$} \\
\hline $\mathrm{A}=\mathrm{NO}_{3}^{-}$ & {$\left[\mathrm{Cd}_{0.67} \mathrm{Al}_{0.33}(\mathrm{OH})_{2}\right]\left(\mathrm{NO}_{3}\right)_{0.27}\left(\mathrm{CO}_{3}\right)_{0.03} .0 .41 \mathrm{H}_{2} \mathrm{O}$} \\
\hline
\end{tabular}




\section{X-Ray Diffraction}

XRD is a useful technique for the characterization of LDHs and it allows the identification of different polymorphs ${ }^{23}$. LDHs share a similar characteristic diffraction pattern with two main peaks at $2 \theta$ values around $11^{\circ}$ and $23^{\circ 25}$. Fig. $3(\mathrm{~B}, \mathrm{C})$ shows the diffraction patterns of different CdAlA LDHs (for $x=0.25$ and $x=0.33$ ). The two main Bragg reflection peaks are observed at $11.3^{\circ}$ and $22.6^{\circ}$ which are indexed as the $(003)$ and (006) reflections, respectively. Thus, using Bragg's equation $(n \lambda=2 d \sin \theta)$ and the equation relating the ' $d$ ' spacing to the $(h k l)$ indices for a rhombohedral unit cell, the lattice parameter $c(c=3 d(003))$ is calculated.

Fig. 3 (A) presents the diffraction patterns of the white polymorph. All the diffraction peaks can be indexed to $\beta-\mathrm{Cd}(\mathrm{OH})_{2}$ in a hexagonal symmetry ${ }^{26}$. Table 2 presents the values of the lattice parameter ' $c$ ' for both polymorphs.

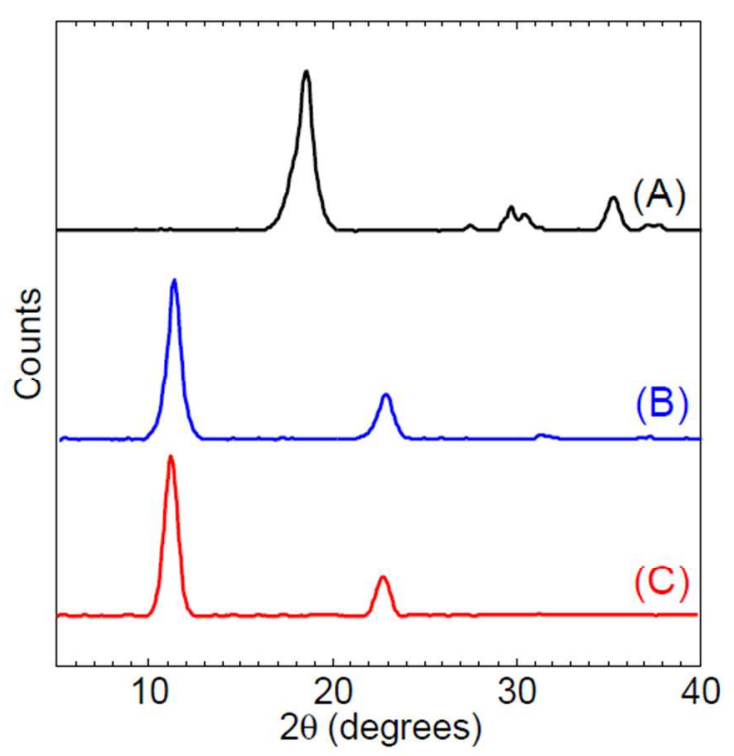

Figure 3. XRD patterns of the white polymorph $\left(\beta-\mathrm{Cd}(\mathrm{OH})_{2}\right)(\mathrm{A})$ and the yellow polymorph (CdAlA LDH) for $x=0.25(\mathrm{~B})$ and $x=0.33(\mathrm{C})$. 
Table 2. Unit cell parameter ' $c$ ' of the $\beta-\mathrm{Cd}(\mathrm{OH})_{2}$ crystals and CdAlA LDHs having different cationic ratios and interlayer anions.

\begin{tabular}{|c|c|c|c|}
\hline & $\mathrm{CdAlCl} \mathrm{LDH}$ & $\mathrm{CdAlNO}_{3} \mathrm{LDH}$ & $\beta-\mathrm{Cd}(\mathrm{OH})_{2}$ \\
\hline$x=0.25$ & $23.68 \AA$ & $23.68 \AA$ & $4.77 \AA$ \\
\hline$x=0.33$ & $23.27 \AA$ & $23.27 \AA$ & $4.77 \AA$ \\
\hline
\end{tabular}

\section{Differential Scanning Calorimetry}

DSC is a common technique used for the thermal analysis of $\mathrm{LDHs}^{27,28}$. In general, DSC measurements show two endothermic peaks ${ }^{28}$. The first peak occurs at a relatively low temperature and corresponds to the loss of adsorbed and interlayer water. The second peak occurs at higher temperatures; it may consist of two stages and it is due to dehydroxylation of the brucite sheets.

In Fig. 4 (B,C), all the CdAlA LDHs show a main heat flow step between $70{ }^{\circ} \mathrm{C}$ and 148 ${ }^{\circ} \mathrm{C}$ corresponding to the loss of adsorbed and interlayer water.

The heat flow at $210^{\circ} \mathrm{C}$ is attributed to $\mathrm{Cd}-\mathrm{OH}$ de-hydroxylation while the peak at 350 ${ }^{\circ} \mathrm{C}$ is due to $\mathrm{Al}-\mathrm{OH}$ de-hydroxylation together with the loss of interlayer anions ${ }^{24,29}$. The shoulder at $300{ }^{\circ} \mathrm{C}$ is attributed to the de-carbonation ${ }^{24}$. In contrast, the DSC spectrum of $\beta-\mathrm{Cd}(\mathrm{OH})_{2}$ (Fig. 4 (A)) shows only one endothermic peak at $210^{\circ} \mathrm{C}$ attributed to $\mathrm{Cd}-\mathrm{OH}$ de-hydroxylation. 


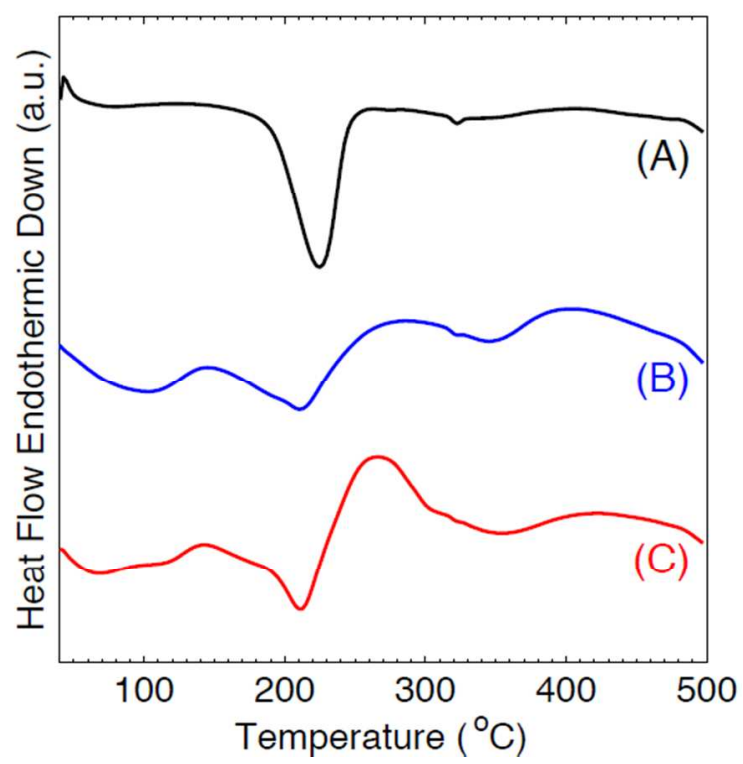

Figure 4. DSC plots of the $\beta-\mathrm{Cd}(\mathrm{OH})_{2}$ crystals (A), CdAlA LDH for $x=0.25$ (B) and $x=$ $0.33(\mathrm{C})$.

\section{FT-IR Spectroscopy}

FT-IR spectroscopy is used to examine the presence of guests anions based on their vibrational modes ${ }^{27}$. Fig. 5 (A, B) shows the FT-IR spectra of CdAlA LDHs with different guest anions. The broad peak at $3450 \mathrm{~cm}^{-1}$, present in both LDHs, is assigned to the $\mathrm{OH}$ stretching vibration of the interlayer and surface bound water. The shoulder at $2950 \mathrm{~cm}^{-1}$ is attributed to the hydrogen bonding between water and anions in the interlayer region ${ }^{27}$. The water bending vibration also gives a peak at $1635 \mathrm{~cm}^{-1}$. The carbonate anions present three peaks at around $1350 \mathrm{~cm}^{-1}, 875 \mathrm{~cm}^{-1}$ and $625 \mathrm{~cm}^{-1}$ that are attributed to the anti-symmetrical stretching mode $v_{3}\left(E^{\prime}\right)$, the out-of-plane bending mode $v_{2}\left(A_{2}{ }^{\prime \prime}\right)$ and the bending angular mode $v_{4}\left(E^{\prime}\right)$, respectively. The symmetric stretching mode $v_{1}\left(A_{1}^{\prime}\right)$ is infrared inactive. The peak at $1355 \mathrm{~cm}^{-1}$ (Fig. $\left.5(\mathrm{~B})\right)$ is assigned to the $v_{3}$ antisymmetric stretching vibration of the $\mathrm{N}-\mathrm{O}$ bond. The peak in the low wavenumber region at $460 \mathrm{~cm}^{-1}$, typical for the brucite structure (Fig. $5(\mathrm{C})$ ), is due to the vibration of 
Cd-O. The sharp peak at $3610 \mathrm{~cm}^{-1}$ (Fig. 5 (C)) is attributed to the O-H stretching mode of the free $\mathrm{Cd}-\mathrm{OH}$ in the $\beta-\mathrm{Cd}(\mathrm{OH})_{2}$. This peak is absent in the CdAlA LDHs because the free $\mathrm{Cd}-\mathrm{OH}$ in the positively charged layers are interacting with the interlayer anions through hydrogen bonding ${ }^{23}$.

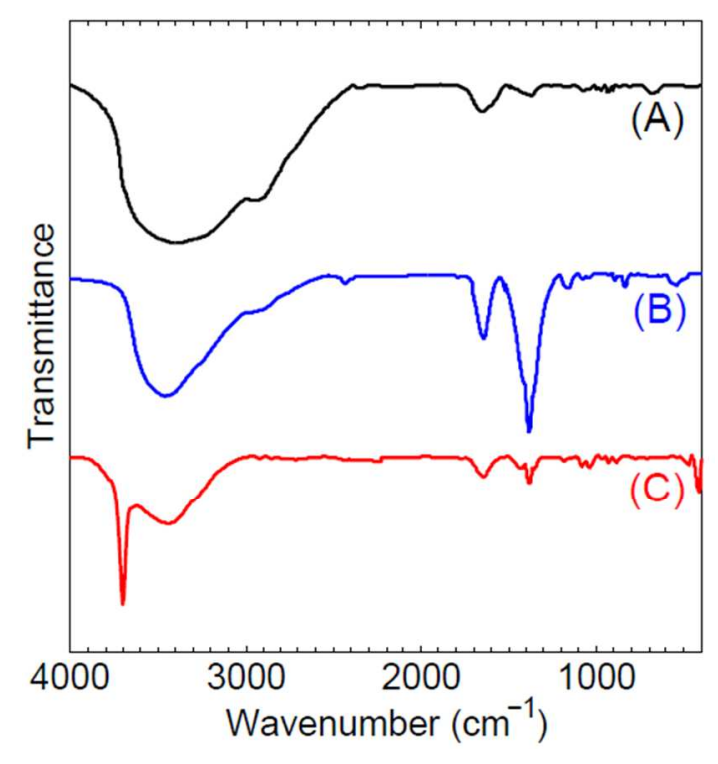

Figure 5. FT-IR spectra of the CdAlA LDH intercalated with chloride (A) and nitrate (B) anions and that of the brucite-like $\beta-\mathrm{Cd}(\mathrm{OH})_{2}$ crystals $(\mathrm{C})$.

\section{${ }^{27}$ Al Solid-State NMR}

${ }^{27} \mathrm{Al}$ SSNMR spectroscopy is used to investigate the Aluminum coordination of the CdAlA LDHs. The chemical shift of the NMR signals of ${ }^{27} \mathrm{Al}$ can be used to differentiate between the octahedral $\left(\mathrm{Al}_{(\text {octa) }}\right)$ and the tetrahedral $\left(\mathrm{Al}_{(\text {tetra })}\right)$ coordinations, where the range of the chemical shift of $\mathrm{Al}_{\text {(tetra) }}$ is $110 \mathrm{ppm}-90 \mathrm{ppm}$ while that of $\mathrm{Al}_{\text {(octa) }}$ is $20 \mathrm{ppm}$ - $0 \mathrm{ppm}^{30}$. All the prepared CdAlA LDHs exhibit a peak at a chemical shift around 15 
ppm (Fig. S5), providing evidence for the octahedral coordination. This slight shift from the perfectly octahedral environment $(\delta=0 \mathrm{ppm})$ is due to minor changes in the $\mathrm{O}-\mathrm{Al}$ bond length ${ }^{31}$.

\section{Kinetics of RhB Intercalation in Different CdAIA LDHs}

The excitation and emission fluorescence spectra of $\mathrm{RhB}$ in the presence of different $\mathrm{Cd}^{2+} / \mathrm{Al}^{3+}$ mixtures in the agar matrix display a blue shift of 3-4 $\mathrm{nm}$ (excitation $\sim 559 \mathrm{~nm}$ and emission $\sim 579 \mathrm{~nm}$ ) compared to those in water (excitation $\sim 562 \mathrm{~nm}$ and emission $\sim$ $583 \mathrm{~nm}$ ). This shift is due to the change in the chemical environment of the probe inside the agar gel matrix compared to that in the water solution ${ }^{20,32}$.

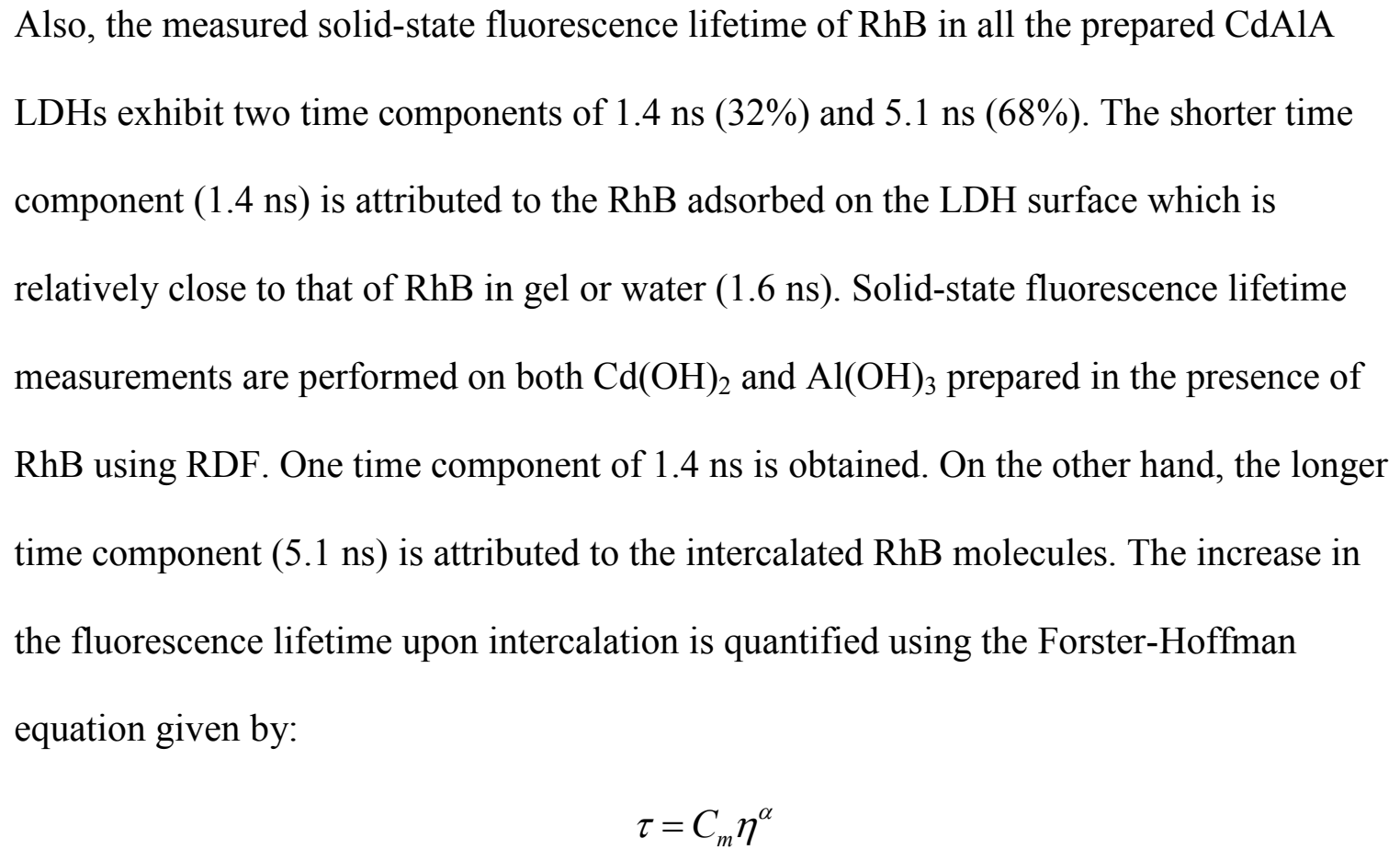


where ' $\tau$ ' is the probe's lifetime, ' $C_{m}$ ' is a constant depending on the medium's temperature and fluorophores' concentration, ' $\alpha$ ' is the probe dependent molecular parameter and ' $\eta$ ' is the medium's viscosity. According to some findings in literature ${ }^{33,34}$, a category of xanthene dyes shows a lifetime dependence on the degree of motion of the organic substituents of the amine group if existed ${ }^{33,34}$. The degree of motion of the $\mathrm{NR}_{1} \mathrm{R}_{2}$ group plays a significant role in determining the rate of internal conversion. In our work, the increase in the probe's $(\mathrm{RhB})$ lifetime can be attributed to the restriction of the mobility of $-\mathrm{NR}_{1} \mathrm{R}_{2}\left(\mathrm{R}_{1}=\mathrm{R}_{2}=\mathrm{C}_{2} \mathrm{H}_{5}\right)$ upon intercalation ${ }^{35}$.

This phenomenon was explained by Drexhage ${ }^{35}$, who studied the lifetime dependence of the xanthene dyes on the amino group's flexibility. Thus, upon excitation and due to the rotation ability along the $\mathrm{C}-\mathrm{N}$ bonds, these dyes show a distortion in their excited state to form a twisted intramolecular charge transfer state (TICT) $)^{36-38}$. This charge transfer results in a non-radiative decay leading to smaller values of the fluorescence lifetime ${ }^{33}$. The intercalation of RhB is further examined via fluorescence microscopy, ${ }^{13} \mathrm{C} \mathrm{SSNMR}$ XRD and ${ }^{27}$ Al SSNMR. The fluorescence image of the extracted CdAlA LDH (Fig. 6) after washing out the gel presents significant fluorescence of CdAlA LDH indicating that the $\mathrm{RhB}$ probes are adsorbed and/or intercalated. 

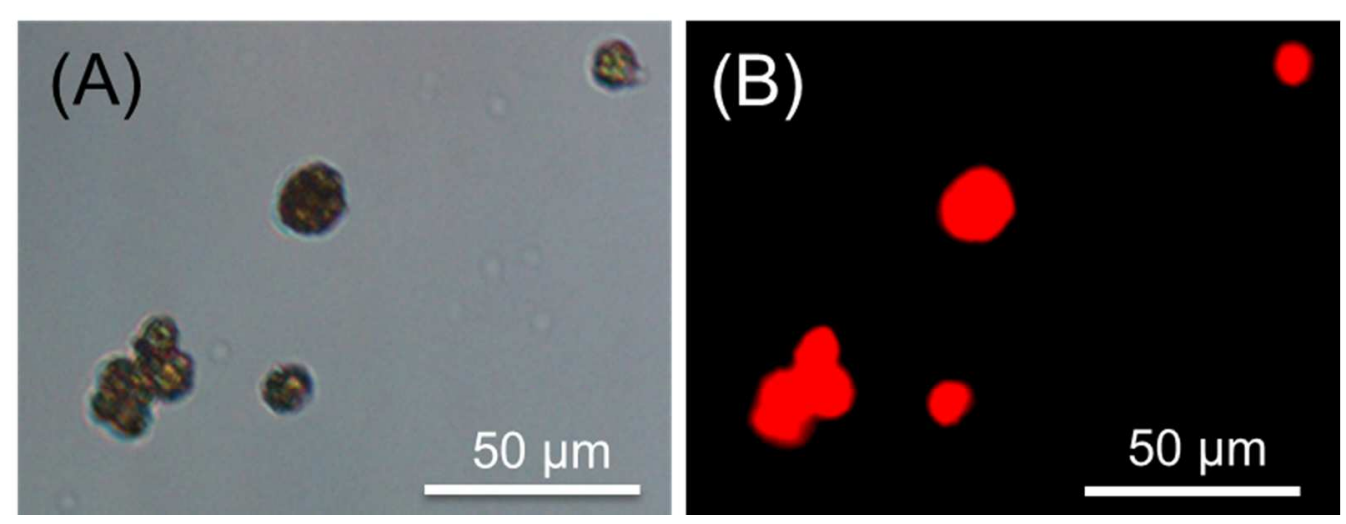

Figure 6. Microscopic image of CdAlA LDH particles intercalated with RhB; under visible light (A) and fluorescence microscopic image of the same particles (B).

Furthermore, the ${ }^{13} \mathrm{C}$ SSNMR spectrum in Fig. S6 shows several aromatic peaks ranging between $105 \mathrm{ppm}$ and $130 \mathrm{ppm}$ as well as several aliphatic peaks in the range between 5 ppm and $40 \mathrm{ppm}$ which gives further indication that the RhB molecules are adsorbed and/or intercalated between the brucite-like sheets of the CdAlA LDH.

Moreover, the XRD patterns of the extracted CdAlA LDHs prepared in the presence of RhB reveal a new reflection at $7.7^{\circ}$ for different CdAlA LDHs (Fig. 7 (A)). This reflection corresponds to the shift of the (003) peak due to the intercalation of the dye. Table 3 shows the calculated lattice parameter ' $c$ ' for different CdAlA LDHs prepared in the presence of $\mathrm{RhB}$. Consequently, the increase in the interlayer spacing value from 23.5 $\AA$ (absence of $\mathrm{RhB}$ ) to $34.5 \AA$ (presence of $\mathrm{RhB}$ ) indicates that the RhB molecules are incorporated into the interlayer region. This shift corresponds to an increase in the interlayer spacing from $3.0 \AA$ to $6.7 \AA$, which matches the side dimension of RhB (Fig. S1 (B)). Therefore, the most probable arrangement of RhB between the LDH's layers (Fig. 7 (B)), assuming that the intercalation of $\mathrm{RhB}$ does not alter the structure of the sheets, is parallel to the brucite-like sheets as shown in (Fig. 7 (C)). 


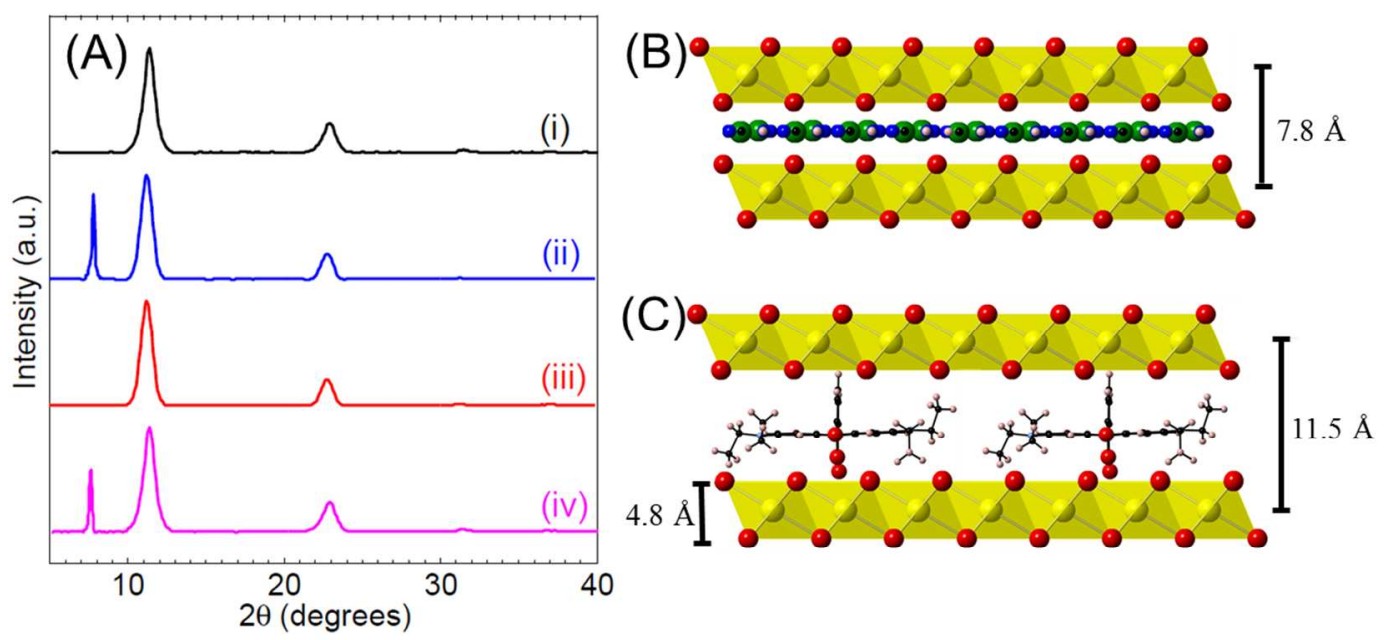

Figure 7. XRD spectra of CdAlA LDH $(x=0.25)(\mathrm{A}(\mathrm{i}))$, CdAlA LDH $(x=0.25)$ intercalated with RhB (A(ii)), CdAlA LDH $(x=0.33)$ (A(iii)), and CdAlA LDH $(x=$ 0.33 ) intercalated with $\mathrm{RhB}(\mathrm{A}(\mathrm{iv}))$. CdAlA brucite-like sheets (B) and probable arrangement of $\mathrm{RhB}$ intercalated between the brucite-like sheets $(\mathrm{C})$.

Table 3. Unit cell parameter ' $c$ ' of different CdAlA LDHs intercalated with RhB probes.

\begin{tabular}{|c|c|c|}
\hline & CdAlCl LDH & $\mathrm{CdAlNO}_{3} \mathrm{LDH}$ \\
\hline$x=0.25$ & $34.42 \AA$ & $34.42 \AA$ \\
\hline$x=0.33$ & $34.42 \AA$ & $34.42 \AA$ \\
\hline
\end{tabular}

Furthermore, upon formation of the different CdAlA LDHs in the gel and in the presence of $\mathrm{RhB}$, the fluorescence intensity decreases in a first exponential decay. The excitation and emission maxima are $554 \mathrm{~nm}$ and $572 \mathrm{~nm}$, respectively; thus, the incorporation of $\mathrm{RhB}$ between the LDH's sheets resulted in a blue shift of these maxima compared to those in the agar matrix. Fig. S7 shows the fluorescence spectra (excitation and emission) of $\mathrm{RhB}$ during the formation of CdAlA LDH. The observed blue shift is due to the interaction between the RhB's xanthene rings and the positive charges of the brucite-like sheets which is examined via ${ }^{27} \mathrm{Al}$ SSNMR (Fig. S8). The ${ }^{27} \mathrm{Al}$ SSNMR spectrum of 
CdAlA LDH intercalated with RhB shows two distinct peaks at $\delta=15 \mathrm{ppm}$ and $\delta=75$ ppm while the non-intercalated CdAlA LDH presents only one peak at $\delta=15 \mathrm{ppm}$. This splitting suggests the interaction of the LDH's sheets with the intercalated RhB molecules leading to a different chemical environment around the aluminum atoms ${ }^{31}$.

The rate constants ' $k$ ' of $\mathrm{RhB}$ intercalation inside the interlayer region of CdAlA LDHs having different cationic ratios and interlayer-anions are calculated by fitting the plots of the variation of the fluorescence signal measured at $\lambda_{\mathrm{em}}(\max )=573 \mathrm{~nm}$ versus time which presents a first exponential fluorescence decay (Fig. 8).
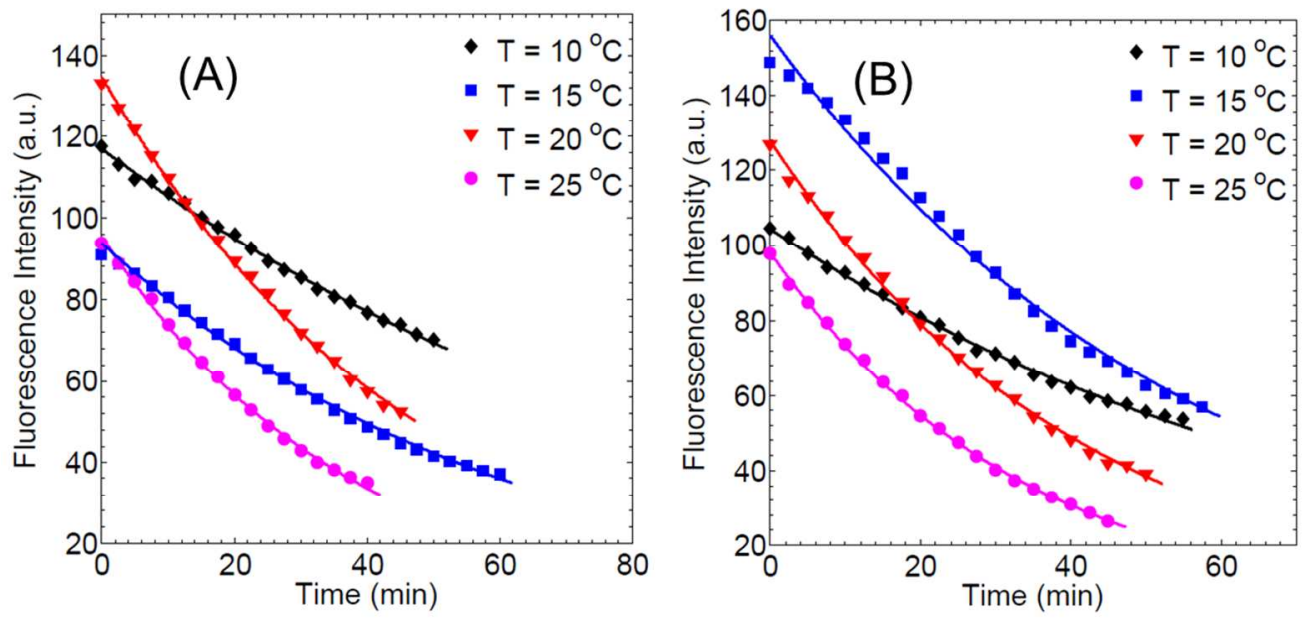

Figure 8. Kinetic plots of the fluorescence intensity of RhB during its intercalation in $\mathrm{CdAlNO}_{3} \mathrm{LDH}$ having a cationic ratio of $x=0.25$ (A) and $x=0.33$ (B). All fits are reported with correlation coefficient $\left(r^{2}\right)$ higher than 0.992 .

Consequently, the activation energies of $\mathrm{RhB}$ intercalation in different CdAlA LDHs are calculated from the Arrhenius equation given by: $\ln k=\ln A-\left(\frac{E a}{R}\right) \frac{1}{T}$

where ' $k$ ' is the rate constant of RhB molecules' intercalation at a given temperature ' $T$ ', and ' $E a$ ' is the corresponding activation energy. Table 4 shows the activation energies of 
RhB intercalation in different CdAlA LDHs. Fig. S9 shows the Arrhenius plots used to calculate the activation energies of $\mathrm{RhB}$ intercalation in $\mathrm{CdAlNO}_{3} \mathrm{LDHs}$ for two different ' $x$ ' values.

Table 4. Activation energies of RhB's intercalation in different CdAlA LDHs.

\begin{tabular}{|c|c|c|}
\hline & $\mathrm{CdAlCl} \mathrm{LDH}$ & $\mathrm{CdAlNO}_{3} \mathrm{LDH}$ \\
\hline$x=0.25$ & $39.2 \pm 0.5 \mathrm{~kJ} \cdot \mathrm{mol}^{-1}$ & $39.0 \pm 0.6 \mathrm{~kJ} \mathrm{~mol}^{-1}$ \\
\hline$x=0.33$ & $41.6 \pm 0.4{\mathrm{~kJ} . \mathrm{mol}^{-1}}^{-1}$ & $41.7 \pm 0.6{\mathrm{~kJ} . \mathrm{mol}^{-1}}^{-1}$ \\
\hline
\end{tabular}

\section{Kinetics of RhB De-Intercalation during the Transition into the $\beta-\mathrm{Cd}(\mathrm{OH})_{2}$}

During the polymorphic transformation of CdAlA LDH into $\beta-\mathrm{Cd}(\mathrm{OH})_{2}$, the fluorescence intensity increases continuously (Fig. S10) until it reaches a plateau at the end of the transition. The excitation and emission maxima of $\mathrm{RhB}$ are recorded to be $559 \mathrm{~nm}$ and $579 \mathrm{~nm}$, respectively. These maxima are red shifted by $\sim 6 \mathrm{~nm}$ compared to those of $\mathrm{RhB}$ intercalated in the $\mathrm{LDH}$ and are equal to those of $\mathrm{RhB}$ in the agar gel matrix. This red shift throughout the transition into $\beta-\mathrm{Cd}(\mathrm{OH})_{2}$ can be assigned to the release of $\mathrm{RhB}$ from the interlayer region of the LDH.

On the other hand, the extracted $\beta-\mathrm{Cd}(\mathrm{OH})_{2}$ crystals show a weak fluorescence (Fig. 9). 

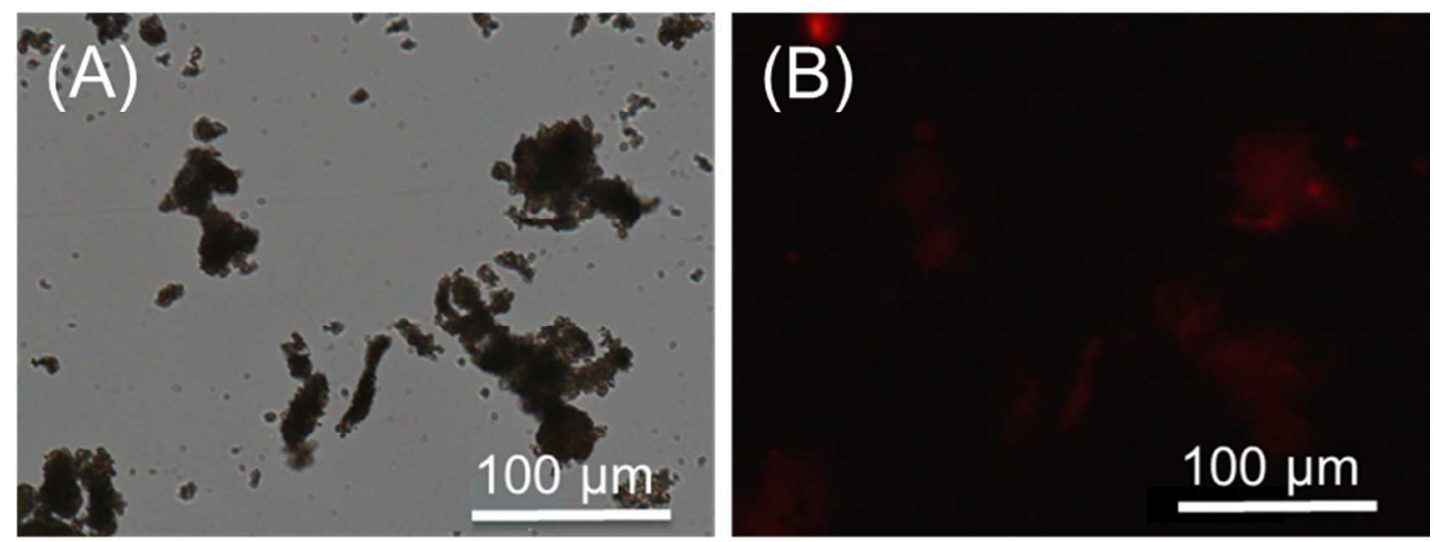

Figure 9. Microscopic image of $\beta-\mathrm{Cd}(\mathrm{OH})_{2}$ prepared in the presence of $\mathrm{RhB}$; under visible light (A) and fluorescence microscopic image of the same particles (B).

Also, the ${ }^{13} \mathrm{C}$ SSNMR spectrum of $\beta-\mathrm{Cd}(\mathrm{OH})_{2}$ solid (Fig. S11) did not exhibit a carbon signal. Both results suggest either the absence of $\mathrm{RhB}$ or the presence of undetectable adsorbed traces. The solid-state fluorescence lifetime presents a one time component of $1.4 \mathrm{~ns}$ which corresponds to the adsorbed $\mathrm{RhB}$ on the surface of $\beta-\mathrm{Cd}(\mathrm{OH})_{2}$. Moreover, identical XRD patterns are obtained for the $\beta-\mathrm{Cd}(\mathrm{OH})_{2}$ crystals prepared in the presence and absence of RhB (Fig. S12). Therefore, all these techniques indicate that while some $\mathrm{RhB}$ molecules remain adsorbed on the brucite surface, the brucite compound $\left(\beta-\mathrm{Cd}(\mathrm{OH})_{2}\right)$ cannot accommodate $\mathrm{RhB}$ molecules in its small cavities.

Similar to the intercalation kinetics, the different rate constants of $\mathrm{RhB}$ de-intercalation during the transition from the $\mathrm{CdAlA} L \mathrm{LH}$ to $\beta-\mathrm{Cd}(\mathrm{OH})_{2}$ are calculated by fitting the plots of the fluorescence intensity variation with time (Fig. 10). The monoexponential fit of the fluorescence suggests that the change of intensity corresponds to the deintercalation of the used probe. Moreover, the corresponding activation energies are determined from the Arrhenius plots (Fig. S13), as previously described. Table 5 
summarizes the calculated activation energies of $\mathrm{RhB}$ de-intercalation during the conversion of different CdAlA LDHs to $\beta-\mathrm{Cd}(\mathrm{OH})_{2}$.
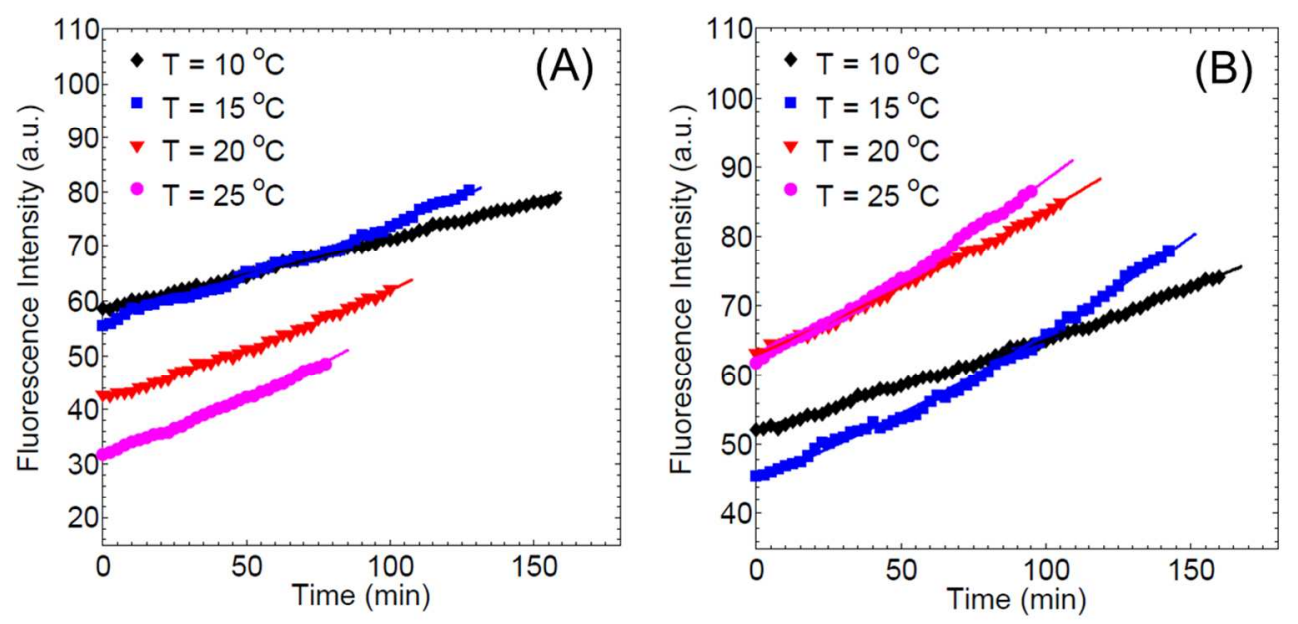

Figure 10. Kinetic plots of the fluorescence intensity of RhB during its de-intercalation from the $\mathrm{CdAlNO}_{3} \mathrm{LDH}$ having a cationic ratio of $x=0.25$ (A) and $x=0.33$ (B). All fits are reported with correlation coefficient $\left(r^{2}\right)$ higher than 0.992 .

Table 5. Activation energies of RhB's de-intercalation from different CdAlA LDHs upon transition into the $\beta-\mathrm{Cd}(\mathrm{OH})_{2}$ crystals.

\begin{tabular}{|c|c|c|}
\hline & $\mathrm{CdAlCl} \mathrm{LDH} / \beta-\mathrm{Cd}(\mathrm{OH})_{2}$ & $\mathrm{CdAlNO}{ }_{3} \mathrm{LDH} / \beta-\mathrm{Cd}(\mathrm{OH})_{2}$ \\
\hline$x=0.25$ & $48.5 \pm 0.3 \mathrm{~kJ} \cdot \mathrm{mol}^{-1}$ & $48.4 \pm 0.9 \mathrm{~kJ} \cdot \mathrm{mol}^{-1}$ \\
\hline$x=0.33$ & $48.7 \pm 0.5 \mathrm{~kJ} \cdot \mathrm{mol}^{-1}$ & $48.8 \pm 0.5 \mathrm{~kJ} \cdot \mathrm{mol}^{-1}$ \\
\hline
\end{tabular}

\section{Proposed Mechanism}

Fluorescence resonance energy transfer (FRET) is a long-range dipole-dipole interaction between the excited electronic state of a donor molecule and the ground state of an acceptor one. The rate of energy transfer depends on several factors, mainly the distance between the donor and acceptor $(\sim 5 \mathrm{~nm})$, the extent of spectral overlap between the acceptor's absorption and donor's emission spectra, and the donor's quantum yield ${ }^{39}$. 
There are two types of RET: the homo-RET where the donor-acceptor probes are chemically identical and the hetero-RET where they are chemically distinct ${ }^{40}$. The homoRET occurs for fluorescent dyes exhibiting small Stokes shift. RhB presents a Stokes shift of $17 \mathrm{~nm}$. Besides, the possibility of the homo-RET for a given fluorescent dye is assessed by examination of the overlap's extent between absorption and emission spectra. Fig. S14 indicates that the homo-RET event can occur in the case of RhB due to the considerable spectral overlap extent between its absorption and emission spectra. Furthermore, in the gel medium, the fluorophores are too far apart due to the low concentration of $\mathrm{RhB}(100 \mathrm{nM})$; consequently, the homo-RET event is unlikely to occur. Moreover, none of the salts present in the medium shows any quenching effect on the fluorescence signal of the involved probe (table 6). Besides, upon formation of the CdAlA LDH, the RhB molecules are intercalated in the interlayer region of the LDH resulting in a local increase in their concentration ${ }^{41}$. Consequently, the average distance between the RhB molecules decreases, which leads to the quenching of the fluorescence signal via homo-RET.

Table 6. Fluorescence intensity of RhB prepared in the presence of different salts.

\begin{tabular}{|c|c|c|c|c|c|c|}
\hline $\begin{array}{c}\text { Mixture } \\
\left(\mathrm{V}_{\text {total }}=3 \mathrm{~mL}\right)\end{array}$ & $\begin{array}{c}\text { Distilled } \\
\text { water }\end{array}$ & $\begin{array}{c}0.1 \mathrm{M} \\
\mathrm{CdCl}_{2}\end{array}$ & $\begin{array}{c}0.1 \mathrm{M} \\
\mathrm{Cd}\left(\mathrm{NO}_{3}\right)_{2}\end{array}$ & $\begin{array}{c}0.1 \mathrm{M} \\
\mathrm{AlCl}_{3}\end{array}$ & $\begin{array}{c}0.1 \mathrm{M} \\
\mathrm{Al}\left(\mathrm{NO}_{3}\right)_{3}\end{array}$ & $\begin{array}{c}1 \mathrm{M} \\
\mathrm{NaOH}\end{array}$ \\
\hline $\begin{array}{c}\text { Fluorescence } \\
\text { Intensity }\end{array}$ & 180 & 178 & 183 & 184 & 179 & 180 \\
\hline
\end{tabular}

On the other hand, the activation energies of $\mathrm{RhB}$ intercalation (table 4) show a difference of approximately $2.5 \mathrm{~kJ} \cdot \mathrm{mol}^{-1}$ for CdAlA LDHs having different cationic 
ratios, where $E a=39.1 \mathrm{~kJ} . \mathrm{mol}^{-1}$ for $x=0.25$ and $41.6 \mathrm{~kJ} \cdot \mathrm{mol}^{-1}$ for $x=0.33 .{ }^{27,42}$. Besides, the basal spacing of LDHs is inversely proportional to its cationic ratio, which is previously verified by the XRD data. Accordingly, the RhB molecules require more energy to intercalate as the basal spacing decreases, which clarifies the $2.5 \mathrm{~kJ} . \mathrm{mol}^{-1}$ difference in the activation energies for different ' $x$ ' values. Besides, a slight difference in the activation energies is observed for the CdAlA LDHs having different interlayer anions $\left(\mathrm{Cl}^{-}\right.$or $\left.\mathrm{NO}_{3}{ }^{-}\right)$. Hence, the intercalation of $\mathrm{RhB}$ in the cavities of $\mathrm{LDHs}$ shows a dependence on the cationic ratio of the corresponding LDH and an independence of the interlayer anions nature.

The de-intercalation of $\mathrm{RhB}$ during the transition from the CdAlA LDHs, with different inter-gallery anions and cationic ratios, into the $\beta$ phase, shows a slight difference in the activation energies which are almost equal to $48.5 \mathrm{~kJ} \mathrm{~mol}^{-1}$. Yet, the difference in the activation energies between intercalation and de-intercalation is $\sim 7 \mathrm{~kJ} \mathrm{~mol}^{-1}$ when $x=$ 0.33 and $\sim 9.4 \mathrm{~kJ} . \mathrm{mol}^{-1}$ when $x=0.25$. This disparity suggests that the stabilization effect of the RhB probes depends on the interlayer spacing between the brucite sheets. Therefore, the further excess in the positive charges as ' $x$ ' becomes larger causes the destabilization of the probes inside the cavities, consequently, less energy is needed to break these interactions.

\section{CONCLUSIONS}

We used the reaction-diffusion framewrok (RDF) combines with in situ fluorescence spectroscopy to study the intercalation and de-intercalation kinetics of a neutral fluorescent probe $(\mathrm{RhB})$ between the layers of $\mathrm{CdAl} \mathrm{LDH}$ as it formed and later 
converted to the brucite-like $\mathrm{Cd}(\mathrm{OH})_{2}$. Concurrently, the co-synthesis and full characterization of the unstable CdAlA LDH and the brucite-like $\mathrm{Cd}(\mathrm{OH})_{2}$ was performed and reported. We are able to determine both the activation energies of intercalation and the de-intercalation of RhB. SSNMR and XRD were used in order to understand the mechanism of intercalation and the stabilization of the dye in the interlayer of the LDH. The fluorescence experiments were used to determine the activation energies of intercalation and de-intercalation of $\mathrm{RhB}$ and clearly demostrated their dependence on the cationic ratio of the corresponding LDH. Moreover, the energies of de-intercalation were steadily higher than those of intercalation indicating, with the aid of SSNMR experiments, that the dyes were stabilized as a result of the probe-brucite sheets interactions.

\section{Acknowledgments}

DS and MG gratefully acknowledge the funding provided by the American University of Beirut Research Board and by the Lebanese National Council for Scientific Research (LCNSR).

\section{Supporting Information}

Characterization of the CdAlA LDH and the $\beta-\mathrm{Cd}(\mathrm{OH})_{2}$ crystals. The structural and spectral properties of $\mathrm{RhB}$ and the proof of its de-intercalation form the brucite crystals. This material is available free of charge via the Internet at http://pubs.acs.org 


\section{References}

(1) Xu, Z. P.; Zhang, J.; Adebajo, M. O.; Zhang, H.; Zhou, C., Catalytic applications of layered double hydroxides and derivatives. Appl. Clay Sci. 2011, 53, 139-150.

(2) Liu, Z.; Ma, R.; Osada, M.; Iyi, N.; Ebina, Y.; Takada, K.; Sasaki, T., Synthesis, anion exchange, and delamination of Co-Al layered double hydroxide: assembly of the exfoliated nanosheet/polyanion composite films and magneto-optical studies. J. Am. Chem. Soc. 2006, 128, 4872-4880.

(3) Tian, G.-L.; Zhao, M.-Q.; Zhang, B.; Zhang, Q.; Zhang, W.; Huang, J.-Q.; Chen, T.-C.; Qian, W.-Z.; Su, D. S.; Wei, F., Monodisperse embedded nanoparticles derived from an atomic metal-dispersed precursor of layered double hydroxide for architectured carbon nanotube formation. J. Mater. Chem. A 2014, 2, 1686-1696.

(4) Wang, Q.; O’Hare, D., Recent advances in the synthesis and application of layered double hydroxide (LDH) nanosheets. Chem. Rev. (Washington, DC, U. S.) 2012, $112,4124-4155$.

(5) Hu, G.; Wang, N.; O'Hare, D.; Davis, J., Synthesis of magnesium aluminium layered double hydroxides in reverse microemulsions. J. Mater. Chem. 2007, 17, 22572266.

(6) Plank, J.; Zou, N.; Zhao, Z.; Dekany, I., Preparation and Properties of a Graphene Oxide Intercalation Compound Utilizing Hydrocalumite Layered Double Hydroxide as Host Structure. Z. Anorg. Allg. Chem. 2014, 640, 1413-1419.

(7) Wu, X.-L.; Wang, L.; Chen, C.-L.; Xu, A.-W.; Wang, X.-K., Water-dispersible magnetite-graphene-LDH composites for efficient arsenate removal. J. Mater. Chem. 2011, 21, 17353-17359. 
(8) Wang, Y.; Peng, W.; Liu, L.; Tang, M.; Gao, F.; Li, M., Enhanced conductivity of a glassy carbon electrode modified with a graphene-doped film of layered double hydroxides for selectively sensing of dopamine. Microchim. Acta 2011, 174, 41-46. (9) Zhao, Y.; Li, F.; Zhang, R.; Evans, D. G.; Duan, X., Preparation of layered double-hydroxide nanomaterials with a uniform crystallite size using a new method involving separate nucleation and aging steps. Chem. Mater. 2002, 14, 4286-4291.

(10) Liang, H.; Meng, F.; Cabán-Acevedo, M.; Li, L.; Forticaux, A.; Xiu, L.; Wang, Z.; Jin, S., Hydrothermal Continuous Flow Synthesis and Exfoliation of NiCo Layered Double Hydroxide Nanosheets for Enhanced Oxygen Evolution Catalysis. Nano Lett. 2015, 15, 1421-1427.

(11) Xu, J.; Gai, S.; He, F.; Niu, N.; Gao, P.; Chen, Y.; Yang, P., A sandwich-type three-dimensional layered double hydroxide nanosheet array/graphene composite: fabrication and high supercapacitor performance. J. Mater. Chem. A 2014, 2, 1022-1031. (12) Wang, B.; Williams, G. R.; Chang, Z.; Jiang, M.; Liu, J.; Lei, X.; Sun, X., Hierarchical NiAl Layered Double Hydroxide/Multiwalled Carbon Nanotube/Nickel Foam Electrodes with Excellent Pseudocapacitive Properties. ACS Appl. Mater. Interfaces 2014, 6, 16304-16311.

(13) Goh, K.-H.; Lim, T.-T.; Dong, Z., Application of layered double hydroxides for removal of oxyanions: a review. Water Res. 2008, 42, 1343-1368.

(14) Paciotti, G. F.; Myer, L.; Weinreich, D.; Goia, D.; Pavel, N.; McLaughlin, R. E.; Tamarkin, L., Colloidal gold: a novel nanoparticle vector for tumor directed drug delivery. Drug delivery 2004, 11, 169-183. 
(15) Williams, G. R.; O'Hare, D., Towards understanding, control and application of layered double hydroxide chemistry. J. Mater. Chem. 2006, 16, 3065-3074.

(16) Du, Y.; Ok, K. M.; O'Hare, D., A kinetic study of the phase conversion of layered cobalt hydroxides. J. Mater. Chem. 2008, 18, 4450-4459.

(17) Korobov, V.; Chibisov, A., Primary processes in the photochemistry of rhodamine dyes. J. Photochem. 1978, 9, 411-424.

(18) Vitha, M. F.; Clarke, R. J., Comparison of excitation and emission ratiometric fluorescence methods for quantifying the membrane dipole potential. Biochim. Biophys. Acta Biomembr. 2007, 1768, 107-114.

(19) Osborne, A. D.; Winkworth, A. C., Viscosity-dependent internal conversion in an aryl-substituted rhodamine dye. Chem. Phys. Lett. 1982, 85, 513-517.

(20) Fikry, M.; Omar, M.; Ismail, L. Z., Effect of host medium on the fluorescence emission intensity of rhodamine B in liquid and solid phase. J. Fluoresc. 2009, 19, 741746.

(21) Hinckley, D. A.; Seybold, P. G.; Borris, D. P., Solvatochromism and thermochromism of rhodamine solutions. Spectrochim. Acta Mol. Biomol. Spectrosc. 1986, $42,747-754$.

(22) El-Batlouni, H.; El-Rassy, H.; Al-Ghoul, M., Cosynthesis, coexistence, and selforganization of $\alpha$-and $\beta$-cobalt hydroxide based on diffusion and reaction in organic gels. J. Phys. Chem. A 2008, 112, 7755-7757.

(23) Rahbani, J.; Khashab, N. M.; Patra, D.; Al-Ghoul, M., Kinetics and mechanism of ionic intercalation/de-intercalation during the formation of $\alpha$-cobalt hydroxide and its 
polymorphic transition to $\beta$-cobalt hydroxide: reaction-diffusion framework. J. Mater. Chem. 2012, 22, 16361-16369.

(24) Kloproggea, J. T.; Kristófb, J.; Frosta, R. L. In Thermogravimetric analysis-mass spectrometry (TGA-MS) of hydrotalcites containing CO3 2-, NO3-, Cl-, SO4 2-or ClO4, 2001, a Clay Odyssey: Proceedings of the 12th International Clay Conference, Bahía Blanca, Argentina, July 22-28, 2001, 2003; Elsevier: 2003; p 451.

(25) Cota, I.; Ramírez, E.; Medina, F.; Layrac, G.; Tichit, D.; Gérardin, C., Influence of the preparation route on the basicity of La-containing mixed oxides obtained from LDH precursors. J. Mol. Catal. A: Chem. 2016, 412, 101-106.

(26) Eskizeybek, V.; Demir, O.; Avci, A.; Chhowalla, M., Synthesis and characterization of cadmium hydroxide nanowires by arc discharge method in de-ionized water. J. Nanopart. Res. 2011, 13, 4673-4680.

(27) Rives, V., Layered double hydroxides: present and future. ed.; Nova Publishers: 2001.

(28) Hamerski, F.; Corazza, M. L., LDH-catalyzed esterification of lauric acid with glycerol in solvent-free system. Appl. Catal., A 2014, 475, 242-248.

(29) Souza, A. D.; Arruda, C. C.; Fernandes, L.; Antunes, M. L.; Kiyohara, P. K.; Salomão, R., Characterization of aluminum hydroxide $\left(\mathrm{Al}(\mathrm{OH})_{3}\right)$ for use as a porogenic agent in castable ceramics. J. Eur. Ceram. Soc. 2015, 35, 803-812.

(30) Al-Bloushi, M.; Davaasuren, B.; Emwas, A. H.; Rothenberger, A., Synthesis and Characterization of the Quaternary Thioaluminogermanates $A\left(\mathrm{AlS}_{2}\right)\left(\mathrm{GeS}_{2}\right)(\mathrm{A}=\mathrm{Na}, \mathrm{K})$. Z. Anorg. Allg. Chem. 2015. 
(31) Vichi, F. M.; Alves, O. L., Preparation of Cd/Al layered double hydroxides and their intercalation reactions with phosphonic acids. J. Mater. Chem. 1997, 7, 1631-1634.

Reisfeld, R.; Zusman, R.; Cohen, Y.; Eyal, M., The spectroscopic behaviour of rhodamine 6G in polar and non-polar solvents and in thin glass and PMMA films. Chem. Phys. Lett. 1988, 147, 142-147.

(33) Magde, D.; Rojas, G. E.; Seybold, P. G., Solvent dependence of the fluorescence lifetimes of xanthene dyes. Photochem. Photobiol. 1999, 70, 737-744.

(34) Arbeloa, T. L.; Arbeloa, F. L.; Bartolomé, P. H.; Arbeloa, I. L., On the mechanism of radiationless deactivation of rhodamines. Chem. Phys. 1992, 160, 123-130.

(35) Drexhage, K., What's ahead in laser dyes? Laser Focus 1973, 9, 35-39.

(36) Tredwell, C. J.; Osborne, A. D., Viscosity dependent internal conversion in the rhodamine dye, fast acid violet 2R. J. Chem. Soc., Faraday Trans. 2 1980, 76, 16271637.

(37) Adhikary, R.; Barnes, C. A.; Trampel, R. L.; Wallace, S. J.; Kee, T. W.; Petrich, J. W., Photoinduced trans-to-cis isomerization of cyclocurcumin. J. Phys. Chem. B 2011, $115,10707-10714$.

Pal, P.; Zeng, H.; Durocher, G.; Girard, D.; Li, T.; Gupta, A. K.; Giasson, R.; Blanchard, L.; Gaboury, L.; Balassy, A., Phototoxicity of some bromine-substituted rhodamine dyes: Synthesis, photophysical properties and application as photosensitizers. Photochem. Photobiol. 1996, 63, 161-168.

(39) Selvin, P. R., Fluorescence resonance energy transfer. Methods Enzymol. 1995, $246,300-334$. 
(40) Tramier, M.; Piolot, T.; Gautier, I.; Mignotte, V.; Coppey, J.; Kemnitz, K.;

Durieux, C.; Coppey-Moisan, M., Homo-FRET versus hetero-FRET to probe homodimers in living cells. Methods Enzymol. 2003, 580-97.

(41) Lee, J. H.; Jung, D.-Y.; Kim, E.; Ahn, T. K., Fluorescein dye intercalated layered double hydroxides for chemically stabilized photoluminescent indicators on inorganic surfaces. Dalton Trans. 2014, 43, 8543-8548.

(42) Cavani, F.; Trifirò, F.; Vaccari, A., Hydrotalcite-type anionic clays: Preparation, properties and applications. Catal. Today 1991, 11, 173-301. 


\title{
For Table of Contents Use Only
}

\section{Dynamics and Mechanism of Intercalation/De-Intercalation of}

\author{
Rhodamine B during the Polymorphic Transformation of the
}

\section{CdAl Layered Double Hydroxide to the Brucite-Like}

\author{
Cadmium Hydroxide \\ Daniel Saliba ${ }^{\dagger}$ Alaa Ezzeddine, ${ }^{\dagger}$ Abdul-Hamid Emwas, ${ }^{\S}$ Niveen M. Khashab,${ }^{\star}$ and \\ Mazen Al-Ghoul ${ }^{*}, \dagger$ \\ ${ }^{\dagger}$ Department of Chemistry, American University of Beirut, P.O.Box 11-0236, Riad El- \\ Solh 1107 2020, Beirut, Lebanon \\ + Smart Hybrid Materials (SHMs) Lab, King Abdullah University of Science and \\ Technology (KAUST), Thuwal 23955-6900, Kingdom of Saudi Arabia \\ §Imaging and Characterization Core Lab, King Abdullah University of Science \\ and Technology (KAUST), Thuwal, Kingdom of Saudi Arabia
}

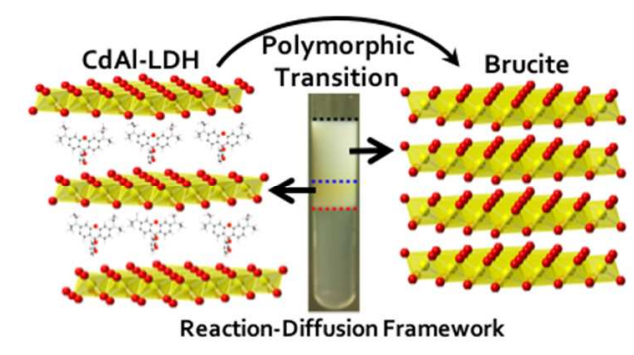

\begin{abstract}
A new method based on reaction-diffusion to study the dynamics of intercalation and deintercalation of a fluorescent probe (Rhodamine B) during the transformation of the unstable cadmium aluminum layered double hydroxide (CdAl LDH) to the brucite-like cadmium hydroxide is presented.
\end{abstract}

